\title{
Stage at Diagnosis
}

National Cancer Institute

\section{Source}

National Cancer Institute. Stage at Diagnosis. NCI Thesaurus. Code C19251.

The extent of cancer spread at the time of the original diagnosis. 